\title{
Doorway Mechanism for Electron Attachment Induced DNA Strand Breaks
}

Jishnu Narayanan S J, Divya Tripathi and Achintya Kumar Dutta*

Department of Chemistry, Indian Institute of Technology Bombay, Powai, Mumbai 400076. 
Table of Content

1. The Nucleoside-Phosphate-Nucleoside system.

2. Optimized cartesian coordinates.

3. Potential energy curve for 5 '-dCMPH.

4. The comparison of EA-EOM-DLPNO-CCSD and CASSCF+NEVPT2 results for the $\mathrm{C}-\mathrm{O}$ and $\mathrm{C}-\mathrm{N}$ bond breaking in $3^{\prime}-\mathrm{dCMPH}$.

5. The effect of microsolvation on the $\mathrm{C}-\mathrm{O}$ bond breaking in $3^{\prime}-\mathrm{dCMPH}$. 


\section{The Nucleoside-Phosphate-Nucleoside system}

Nucleobases in a DNA double-helix have restricted degrees of freedom due to hydrogenbonding and pi-stacking interaction with other nucleobases. Whereas, in short DNA singlestrands such as a dinucleotide, the nucleobases become highly flexible. Therefore, geometry optimization of a dinucleotide most often results in a structure that does not include the pistacking interaction between the nucleobases. To preserve the relative orientation of the cytosine nucleobases in the nucleoside-phosphate-nucleoside (NPN) system, we constructed a DNA decamer with the dinucleotide of interest $(\mathrm{dCpdCp})$ located approximately at the center of one DNA strand, using Avogadro. ${ }^{1}$ The decamer was optimized via the multilayer QM/XTB method with electrostatic embedding. The QM region consisted of $\mathrm{dCpdCp}$ and the rest of the decamer constituted the XTB region. The QM region, treated at BP86/def2-SVP level of theory, alone was optimized while the XTB region's geometry remained constant. DFT was chosen over RI-MP2 due to the large size of the QM region. The optimized geometry of the QM region was isolated from the decamer, and the terminal phosphate group at the 5 ' end was replaced with a hydroxyl group to form the NPN system. This was done because we have not considered the terminal phosphate group's influence on the SSB process. The NPN system was then subjected to a constrained optimization at the BP86/def2-TZVP level, where the relative orientation of the two cytosine nucleobases was kept constant. The intermediate geometries for constructing the potential energy curve (PEC) were generated similar to $3^{\prime}-\mathrm{dCMPH}$. Due to the large size of the system, we have chosen the multilayer DLPNO-EA-EOM-CCSD method in $\mathrm{ORCA}^{2}$ to model the PEC for SSB at $5^{\prime} \mathrm{C}-\mathrm{O}$ and $3^{\prime} \mathrm{C}-\mathrm{O}$ sites. Both nucleobases were kept at the LOOSEPNO truncation level, whereas the NORMALPNO truncation level was chosen for the sugar-phosphate backbone. The cytosine-DNA backbone interaction and cytosine-cytosine interactions were also considered under the LOOSEPNO level. 
Optimized cartesian coordinates.

\section{NPN neutral geometry obtained via constrained optimization at BP86/def2-TZVP level of theory.}

$\begin{array}{llll}\mathrm{H} & -13.05329 & -7.11176 & 4.83652 \\ \mathrm{O} & -12.63035 & -7.19437 & 3.96606 \\ \mathrm{C} & -13.63233 & -7.60505 & 3.02077 \\ \mathrm{H} & -14.47792 & -6.89597 & 3.00565 \\ \mathrm{H} & -14.02008 & -8.61022 & 3.27149 \\ \mathrm{C} & -13.02203 & -7.65515 & 1.62742 \\ \mathrm{H} & -13.74479 & -8.15464 & 0.95953 \\ \mathrm{O} & -12.78234 & -6.32453 & 1.14104 \\ \mathrm{C} & -11.40701 & -6.15057 & 0.74714 \\ \mathrm{H} & -11.30937 & -6.14123 & -0.34740 \\ \mathrm{~N} & -10.97271 & -4.81874 & 1.17057 \\ \mathrm{C} & -11.09570 & -4.46648 & 2.47049 \\ \mathrm{H} & -11.39710 & -5.26505 & 3.15273 \\ \mathrm{C} & -10.83361 & -3.21066 & 2.92914 \\ \mathrm{H} & -10.93039 & -2.95954 & 3.98309 \\ \mathrm{C} & -10.53436 & -3.84754 & 0.18234 \\ \mathrm{O} & -10.43929 & -4.19012 & -0.98866 \\ \mathrm{~N} & -10.27257 & -2.58428 & 0.64917 \\ \mathrm{C} & -10.40705 & -2.27367 & 1.92791 \\ \mathrm{~N} & -10.08112 & -0.99089 & 2.28672 \\ \mathrm{H} & -9.94956 & -0.34433 & 1.51372 \\ \mathrm{H} & -10.45089 & -0.61101 & 3.14995 \\ \mathrm{C} & -10.64227 & -7.31173 & 1.39854 \\ \mathrm{H} & -10.29117 & -7.02271 & 2.39928 \\ \mathrm{H} & -9.78072 & -7.62032 & 0.79715 \\ \mathrm{C} & -11.68124 & -8.41825 & 1.55876 \\ \mathrm{H} & -11.50387 & -9.02585 & 2.45474 \\ \mathrm{O} & -11.76863 & -9.32302 & 0.41527 \\ \mathrm{P} & -10.69033 & -10.45771 & 0.06434 \\ \mathrm{O} & -11.27783 & -11.56509 & -0.71114 \\ \mathrm{O} & -10.02713 & -10.85005 & 1.48210 \\ \mathrm{O} & -9.45072 & -9.68982 & -0.61193 \\ \mathrm{C} & -9.67079 & -9.13573 & -1.94047 \\ \mathrm{H} & -10.66942 & -8.67548 & -1.98898 \\ \mathrm{H} & -9.61531 & -9.94621 & -2.68175 \\ \mathrm{C} & -8.61993 & -8.09755 & -2.25182 \\ \mathrm{H} & -8.83559 & -7.73348 & -3.27862 \\ \mathrm{O} & -8.69039 & -7.01371 & -1.32349 \\ \mathrm{C} & -7.51731 & -6.22934 & -1.60476 \\ \mathrm{H} & -7.66830 & -5.62524 & -2.51194 \\ \mathrm{H} & -7.29007 & -5.26361 & -0.54543 \\ & -7.27876 & -5.62349 & 0.76409 \\ & -7.59130 & -6.64679 & 0.97638\end{array}$




$\begin{array}{llll}\mathrm{C} & -6.92389 & -4.75069 & 1.74881 \\ \mathrm{H} & -6.92580 & -5.05247 & 2.79408 \\ \mathrm{C} & -6.95406 & -3.89739 & -0.94571 \\ \mathrm{O} & -6.94101 & -3.61613 & -2.13563 \\ \mathrm{~N} & -6.61651 & -3.03196 & 0.06112 \\ \mathrm{C} & -6.58037 & -3.42481 & 1.32199 \\ \mathrm{~N} & -6.16055 & -2.50508 & 2.24600 \\ \mathrm{H} & -6.11031 & -1.54582 & 1.91640 \\ \mathrm{H} & -6.38602 & -2.64769 & 3.22275 \\ \mathrm{C} & -6.39380 & -7.27576 & -1.79802 \\ \mathrm{H} & -5.85962 & -7.43755 & -0.85113 \\ \mathrm{H} & -5.66886 & -6.95027 & -2.55534 \\ \mathrm{C} & -7.14282 & -8.55154 & -2.25432 \\ \mathrm{H} & -6.99593 & -9.37250 & -1.53351 \\ \mathrm{O} & -6.84032 & -8.99567 & -3.58080 \\ \mathrm{H} & -10.03470 & -11.81966 & 1.57847 \\ \mathrm{H} & -6.00022 & -9.48357 & -3.55510\end{array}$

Cartesian Coordinates optimized at RI-MP2 level of theory using def2-TZVP basis set $3^{\prime}$-dCMPH neutral
$\begin{array}{llll}\mathrm{O} & 0.000000 & 0.000000 & 0.000000\end{array}$
C $\quad 0.000000 \quad 0.000000 \quad 1.424630$
$\begin{array}{llll}\text { C } & 1.433636 & 0.000000 & 1.898716\end{array}$
O $2.045066-1.247133 \quad 1.566543$
$\begin{array}{llll}\text { C } & 2.288529 & 1.097900 & 1.257161\end{array}$
$\begin{array}{llll}\text { O } & 3.187664 & 1.589820 & 2.277374\end{array}$
C $\quad 3.065666 \quad 0.354431 \quad 0.192539$
C $\quad 3.238370 \quad-1.020284 \quad 0.823404$
N $3.375175-2.095533-0.142782$
C $\quad 4.679190 \quad-2.602485-0.395773$
$\begin{array}{llll}\mathrm{O} & 5.636417 & -2.093184 & 0.166541\end{array}$
$\begin{array}{llll}\mathrm{N} & 4.769070 & -3.654979 & -1.268688\end{array}$
C $\quad 3.706047 \quad-4.079385-1.910411$
$\begin{array}{llll}\mathrm{N} & 3.884885 & -5.089161 & -2.809326\end{array}$
$\begin{array}{llll}\text { C } & 2.404779 & -3.516716 & -1.748260\end{array}$
$\begin{array}{llll}\text { C } & 2.290441 & -2.523208 & -0.831654\end{array}$
$\begin{array}{llll}\mathrm{H} & -0.500848 & 0.892242 & 1.819492\end{array}$
$\begin{array}{llll}\mathrm{H} & -0.499805 & -0.890696 & 1.819420\end{array}$
$\begin{array}{llll}\mathrm{H} & 1.446716 & 0.127104 & 2.986246\end{array}$
H $\quad 4.119079 \quad-1.069970 \quad 1.464877$
H $\quad 2.447114 \quad 0.266684 \quad-0.702924$
$\begin{array}{llll}\mathrm{H} & 4.013403 & 0.830432 & -0.052599\end{array}$
$\begin{array}{llll}\mathrm{H} & 1.681764 & 1.916494 & 0.867598\end{array}$
$\begin{array}{llll}\mathrm{H} & 1.356328 & -2.029282 & -0.591620\end{array}$
$\mathrm{H} \quad 1.546898 \quad-3.864573 \quad-2.305810$
$\mathrm{H} \quad 4.775122 \quad-5.561358 \quad-2.756703$
H $3.087726 \quad-5.638587 \quad-3.082575$ 


$\begin{array}{lrrc}\mathrm{P} & 3.600717 & 3.112625 & 2.321249 \\ \mathrm{O} & 2.217941 & 3.928324 & 2.329312 \\ \mathrm{O} & 4.100557 & 3.339774 & 0.826906 \\ \mathrm{O} & 4.505622 & 3.467221 & 3.413320 \\ \mathrm{H} & -0.917708 & 0.021227 & -0.298153 \\ \mathrm{H} & 2.070978 & 4.297472 & 3.212098 \\ \mathrm{H} & 4.553452 & 4.188634 & 0.723522\end{array}$

\section{3'-dCMPH anion}

$\begin{array}{cccc}\mathrm{O} & 0.000000 & 0.000000 & 0.000000 \\ \mathrm{C} & 0.000000 & 0.000000 & 1.406600 \\ \mathrm{C} & 1.387136 & 0.000000 & 2.037257 \\ \mathrm{O} & 2.032750 & -1.267277 & 1.938635 \\ \mathrm{C} & 2.330266 & 0.992554 & 1.374621 \\ \mathrm{O} & 3.284842 & 1.428219 & 2.392197 \\ \mathrm{C} & 3.026917 & 0.158624 & 0.323033 \\ \mathrm{C} & 2.990193 & -1.273701 & 0.880474 \\ \mathrm{~N} & 2.628668 & -2.258379 & -0.123336 \\ \mathrm{C} & 3.603859 & -2.432551 & -1.117163 \\ \mathrm{O} & 4.712371 & -1.895383 & -0.937294 \\ \mathrm{~N} & 3.302595 & -3.175834 & -2.214249 \\ \mathrm{C} & 2.042591 & -3.615260 & -2.346720 \\ \mathrm{~N} & 1.812609 & -4.327722 & -3.539986 \\ \mathrm{C} & 1.012514 & -3.380788 & -1.458215 \\ \mathrm{C} & 1.262046 & -2.575350 & -0.319012 \\ \mathrm{H} & -0.518079 & 0.910613 & 1.729991 \\ \mathrm{H} & -0.547688 & -0.860511 & 1.815697 \\ \mathrm{H} & 1.286355 & 0.226701 & 3.104809 \\ \mathrm{H} & 3.956523 & -1.560843 & 1.294950 \\ \mathrm{H} & 2.459907 & 0.198704 & -0.607510 \\ \mathrm{H} & 4.050732 & 0.465561 & 0.120957 \\ \mathrm{H} & 1.802587 & 1.860081 & 0.974599 \\ \mathrm{H} & 0.727381 & -2.778786 & 0.609230 \\ \mathrm{H} & 0.017230 & -3.767411 & -1.644042 \\ \mathrm{H} & 2.690797 & -4.710048 & -3.869806 \\ \mathrm{H} & 1.113178 & -5.049715 & -3.428028 \\ \mathrm{P} & 3.837935 & 2.903574 & 2.387031 \\ \mathrm{O} & 2.566471 & 3.876156 & 2.394418 \\ \mathrm{O} & 4.313266 & 3.188882 & 0.891561 \\ \mathrm{O} & 4.791103 & 3.155227 & 3.472821 \\ \mathrm{H} & 0.363643 & -0.894357 & -0.284978 \\ \mathrm{H} & 2.530371 & 4.321237 & 3.251656 \\ \mathrm{H} & 4.918761 & 2.504226 & 0.573108\end{array}$

\section{5'-dCMPH neutral}
$\mathrm{H} \quad-1.78500$
$8.45400 \quad-1.21600$
O $\quad-1.68000$
$8.97900-0.40100$
P $\quad-0.10400$
9.20800
$-0.09900$ 


$\begin{array}{lrrr}\mathrm{O} & -0.12600 & 10.61100 & 0.68700 \\ \mathrm{O} & 0.77100 & 9.07700 & -1.27700 \\ \mathrm{O} & 0.28200 & 8.20600 & 1.07800 \\ \mathrm{C} & -0.54700 & 8.02400 & 2.25900 \\ \mathrm{C} & 0.09800 & 6.98300 & 3.15800 \\ \mathrm{O} & 0.08500 & 5.70400 & 2.49800 \\ \mathrm{C} & 1.56900 & 7.27400 & 3.57600 \\ \mathrm{O} & 1.77700 & 7.11100 & 4.98200 \\ \mathrm{C} & 2.36400 & 6.28900 & 2.71300 \\ \mathrm{C} & 1.39800 & 5.10900 & 2.55700 \\ \mathrm{~N} & 1.59600 & 4.28900 & 1.37000 \\ \mathrm{C} & 1.94100 & 2.88700 & 1.54600 \\ \mathrm{O} & 2.09300 & 2.45300 & 2.68400 \\ \mathrm{~N} & 2.07600 & 2.14200 & 0.40800 \\ \mathrm{C} & 1.92800 & 2.69200 & -0.78900 \\ \mathrm{~N} & 2.12000 & 1.87800 & -1.86600 \\ \mathrm{C} & 1.60400 & 4.07400 & -0.99200 \\ \mathrm{C} & 1.44100 & 4.82800 & 0.13100 \\ \mathrm{H} & -0.63500 & 8.98100 & 2.79700 \\ \mathrm{H} & -1.54600 & 7.68800 & 1.94500 \\ \mathrm{H} & -0.51600 & 6.93100 & 4.07600 \\ \mathrm{H} & 1.46700 & 4.39400 & 3.39200 \\ \mathrm{H} & 2.57000 & 6.73600 & 1.73000 \\ \mathrm{H} & 3.31600 & 6.00500 & 3.17800 \\ \mathrm{H} & 1.84200 & 8.31700 & 3.37200 \\ \mathrm{H} & 1.16900 & 5.88400 & 0.09600 \\ \mathrm{H} & 1.48700 & 4.51200 & -1.98100 \\ \mathrm{H} & 2.24200 & 0.88800 & -1.68500 \\ \mathrm{H} & 1.86500 & 2.17800 & -2.79700 \\ \mathrm{H} & 1.66400 & 6.17100 & 5.20900 \\ \mathrm{H} & -0.25700 & 11.36500 & 0.08500\end{array}$




\section{Potential energy curve of 5'-dCMPH}

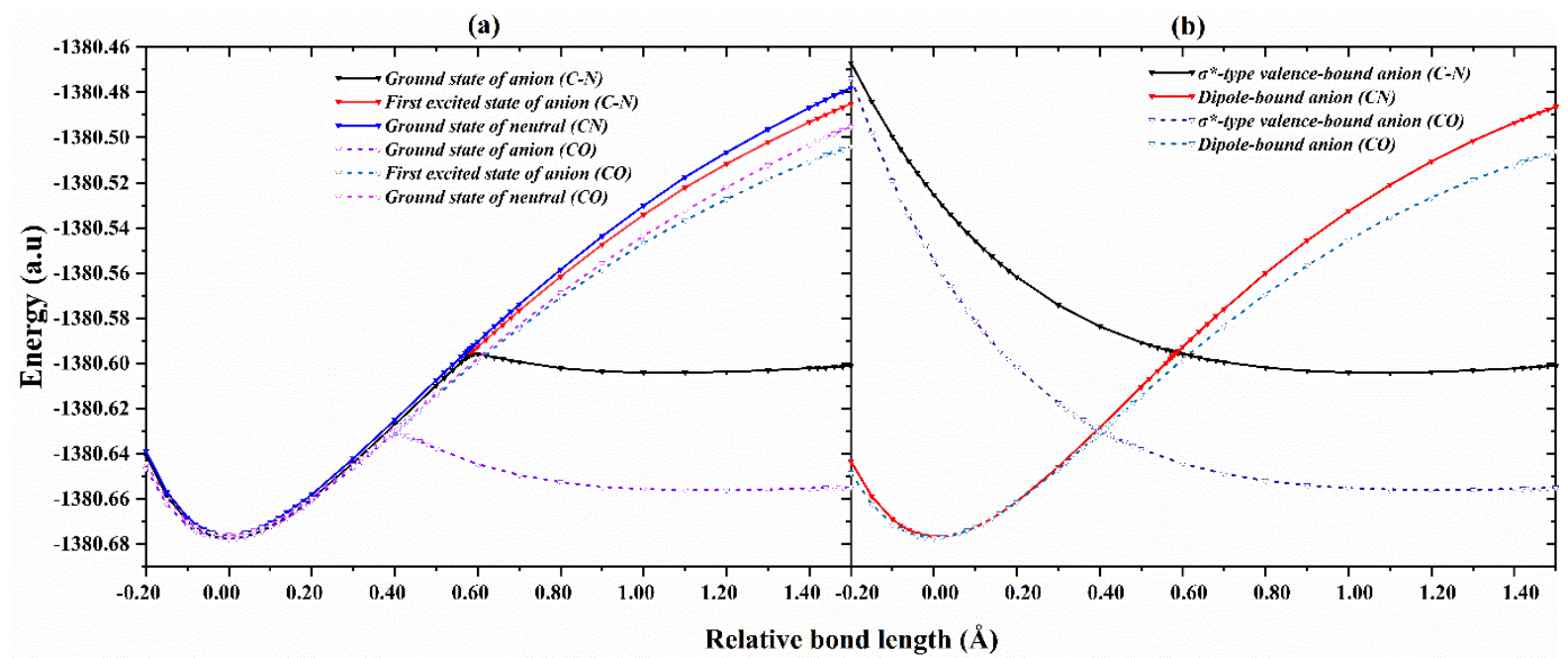

Figure S1. a) Adiabatic PEC and b) diabatic PEC for C-O and C-N bond cleavage for 5'dCMPH. The bond lengths are reported relative to the equilibrium value. 


\section{The comparison of EA-EOM-DLPNO-CCSD and CASSCF-NEVPT2 results.}

In the equation of motion approach, the target state is generated from the single-reference coupled cluster wave-function (based on a closed shell Hartree-Fock in the present case) by the action of a linear excitation operator. The failure of the single-reference coupled cluster method based on the restricted Hartree-Fock method for potential energy surface generally happens when a closed-shell system dissociates into two open-shell fragments. ${ }^{3}$ However, in the present case, the nucleotide in the neutral state dissociated into two closed-shell fragments. Moreover, although EOM-CCSD is a single reference theory, it can include the nondynamic correlation by generating the near degenerate target state configurations from the reference state and can take care of certain multi-reference situations. For the particular case of EA-EOM-CCSD, it gives identical energies as the $(1,0)$ sector of the Fock space multi-reference coupled cluster (FSMRCC). ${ }^{4}$ The FSMRCC and the corresponding EOM-CCSD analog have been successfully used to simulate potential energy curves for single bond stretching of doublet molecules. ${ }^{5,6}$ Therefore, we believe the EOM-CCSD method gives qualitatively correct potential energy curves in the present case. To further verify our conclusion, we have performed some preliminary CASSCF+NEVPT2 investigations for the $\mathrm{C}-\mathrm{O}$ and $\mathrm{C}-\mathrm{N}$ bond stretching of $3^{\prime}-$ dCMPH. Selecting a large active space using a basis set with a large number of diffuse functions is a tricky job. Therefore, a smaller cc-pVDZ with additional diffuse 5s5p4d functions has been used for the calculation. The additional diffuse functions were added to an atom located near the positive end of the dipole moment vector. We chose an active space with five electrons distributed among five orbitals. The active orbitals for $\mathrm{C}-\mathrm{O}$ and $\mathrm{C}-\mathrm{N}$ bond breaking are presented in Figure S2. The CASSCF calculations were followed by strongly contracted n-electron valence state perturbation theory (NEVPT2) calculations to include the dynamic correlation. The EA-EOM-DLPNO-CCSD calculations were performed using the same setting as in the manuscript. Figure $S 3$ presents the adiabatic and diabatic potential energy surface for the $\mathrm{C}-\mathrm{O}$ bond stretching in $3^{\prime}-\mathrm{dCMPH}$. The coupling constant in EA-EOMDLPNO-CCSD and CASSCF+NEVPT2 for C-O bond stretching is $44.94 \mathrm{meV}$ and $7.07 \mathrm{meV}$, respectively. The rate of electron transfer in EA-EOM-DLPNO-CCSD and $\mathrm{CASSCF}+\mathrm{NEVPT} 2$ are $3.6 \times 10^{-5} \mathrm{~s}^{-1}$ and $3.9 \times 10^{-6} \mathrm{~s}^{-1}$, respectively. Figure S4 presents the adiabatic and diabatic potential energy curve for the $\mathrm{C}-\mathrm{N}$ bond stretching in $3^{\prime}-\mathrm{dCMPH}$. The coupling constant in EA-EOM-DLPNO-CCSD and CASSCF+NEVPT2 for CN bond stretching is $22 \mathrm{meV}$ and $6.43 \mathrm{meV}$, respectively. The rates of electron transfer to $\mathrm{C}-\mathrm{N} \sigma^{*}$ state are near zero (less than $10^{-20} \mathrm{~s}^{-1}$ ) in both EA-EOM-DLPNO-CCSD and CASSCF+NEVPT2 
results. Although the absolute rates of electron transfer are slightly different in EA-EOMDLPNO-CCSD and CASSCF+NEVPT2 methods, they follow the same qualitative trend. The electron transfer, which leads to cleavage of $\mathrm{C}-\mathrm{N}$ bond, is extremely slow compared to the electron transfer leading to $\mathrm{CO}$ bond rupture in both the methods and is consistent with available experimental results. One should note that the results from the CASSCF+NEVPT2 method are much dependent upon the selected active space. However, the study of active space convergence of CASSCF+NEVPT2 results for the electron attachment induced bond breaking is outside the scope of the present manuscript and will be followed in a separate study. 
(i)
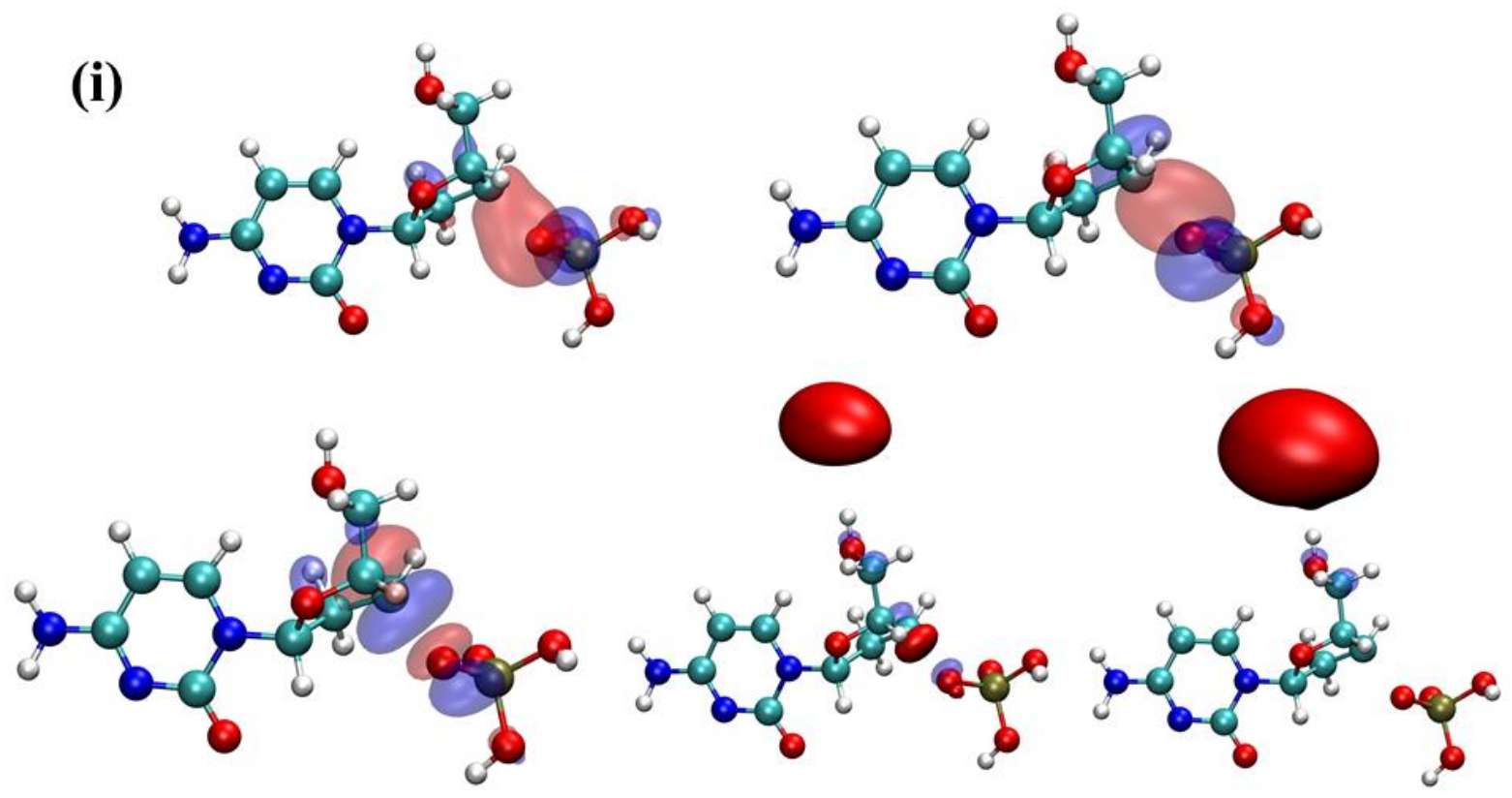

(ii)
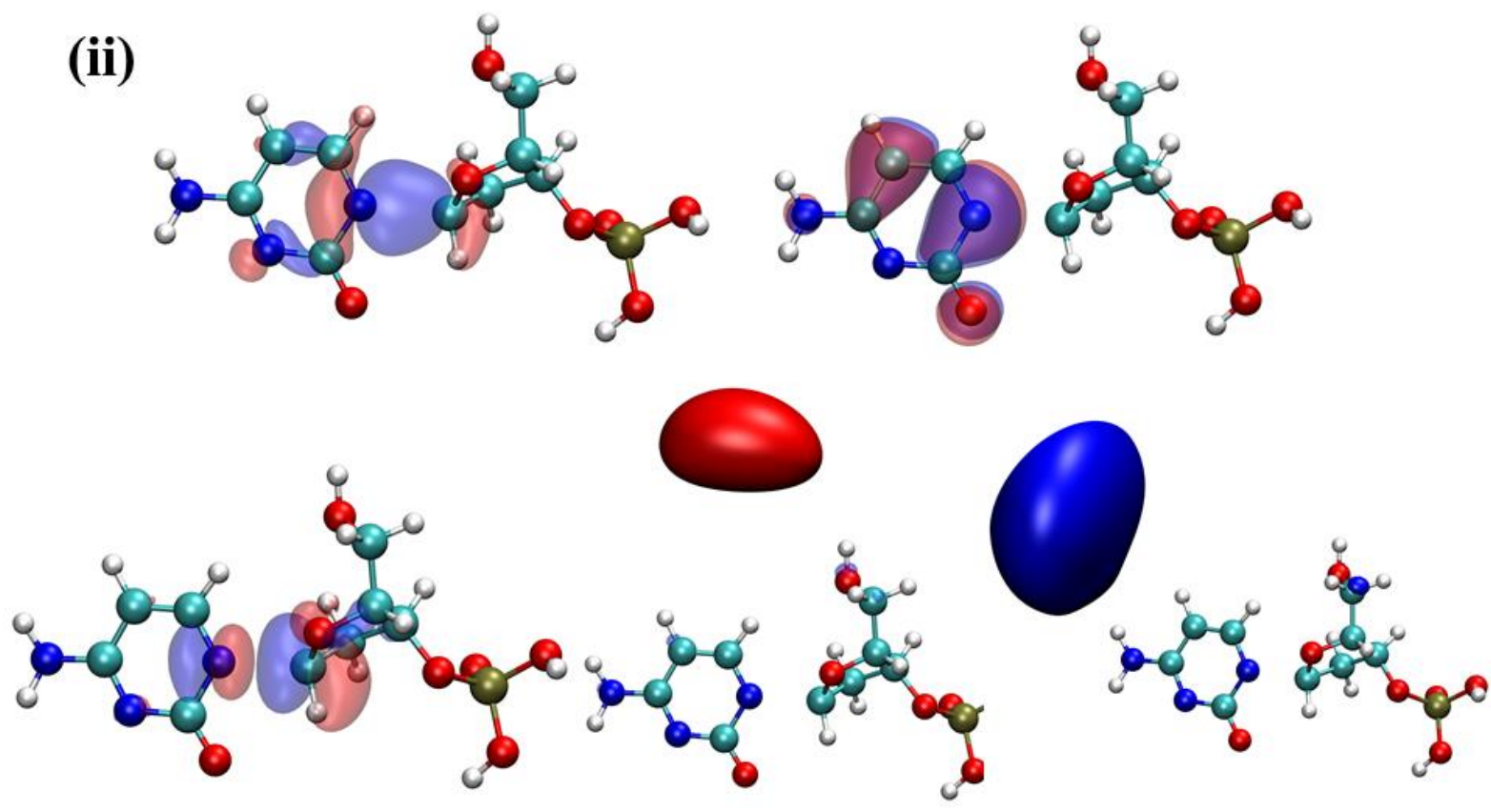

Figure S2. Orbitals included in the active space in the CASSCF calculation for (i) $\mathrm{C}-\mathrm{O}$ and (ii) $\mathrm{C}-\mathrm{N}$ bond cleavage. 


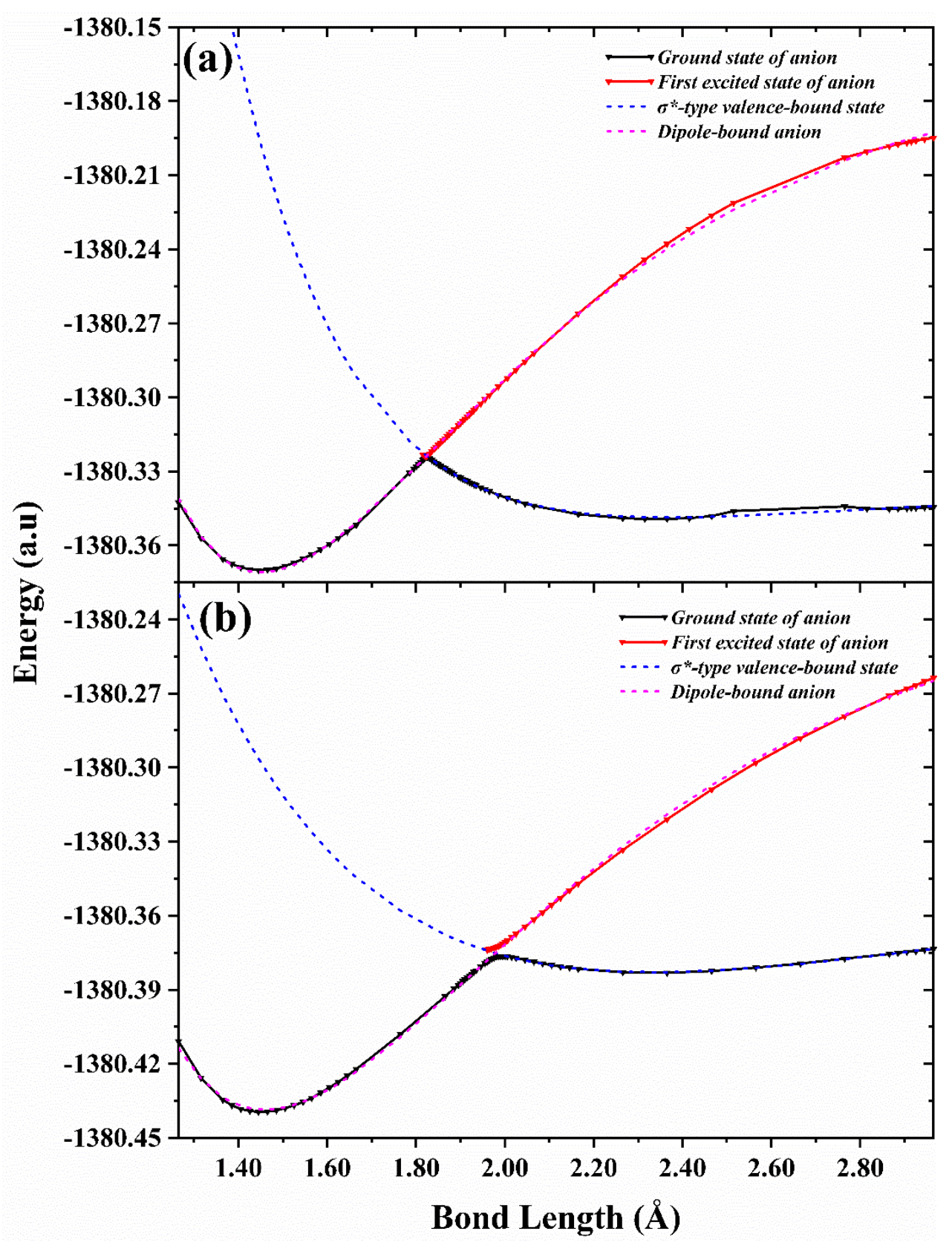

Figure S3. Adiabatic and diabatic PECs for 3'-dCMPH C-O bond cleavage calculated at (a) CASSCF+NEVPT2/cc-pVDZ(+5s5p4d) and at (b) EA-EOM-DLPNO-CCSD/ cc$p V D Z(+5 s 5 p 4 d)$ level of theories. 


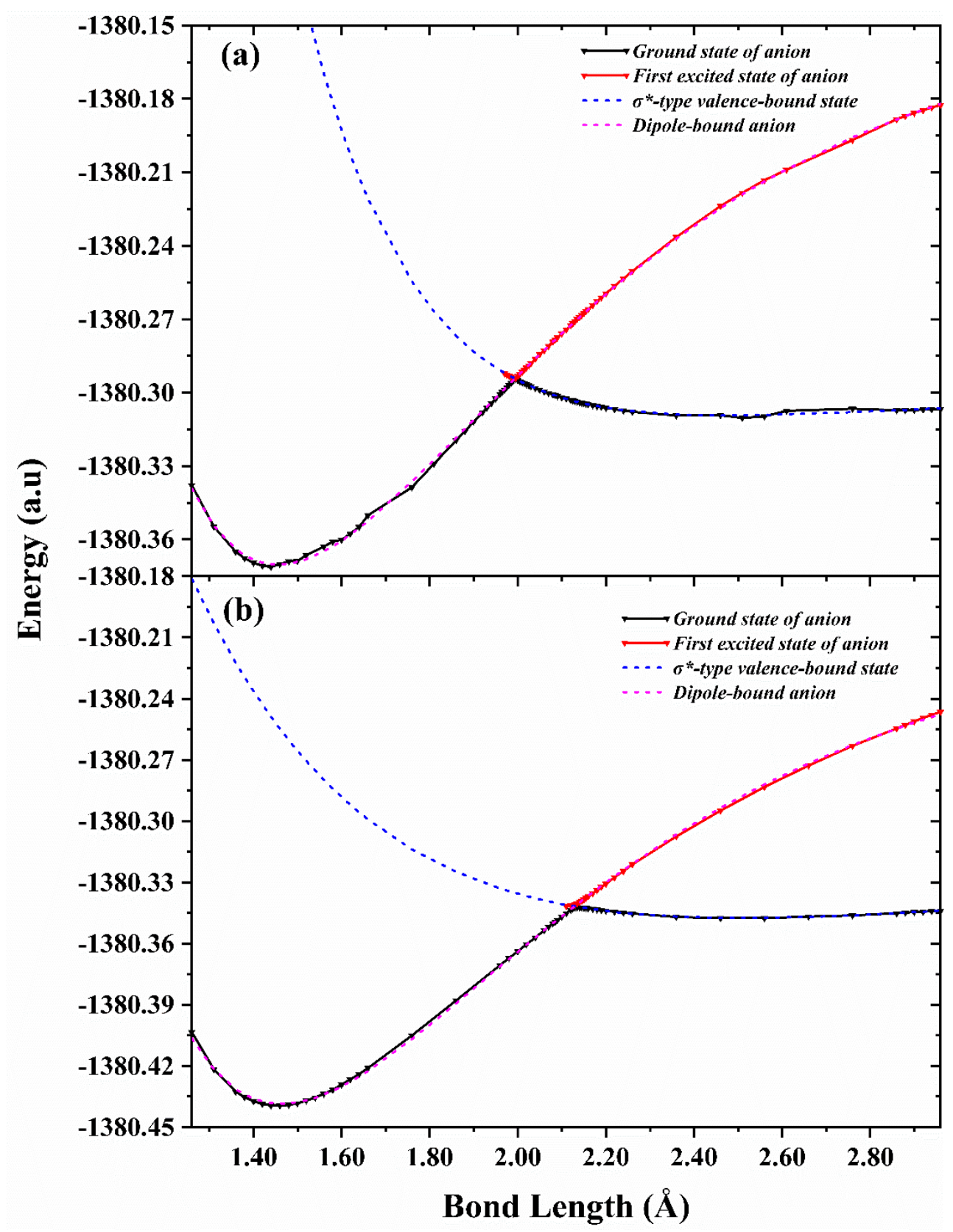

Figure S4. Adiabatic and diabatic PECs for 3'-dCMPH C-N bond cleavage calculated at (a) CASSCF+NEVPT2/cc-pVDZ $(+5 s 5 p 4 d)$ and at (b) EA-EOM-DLPNO-CCSD/ cc$p V D Z(+5 s 5 p 4 d)$ level of theories. 


\section{The effect of microsolvation on the $\mathrm{C}-\mathrm{O}$ bond breaking in $3^{\prime}$-dCMPH.}

To understand the effect of an aqueous environment on the single-strand break induced by lowenergy electrons, we studied the $3^{\prime} \mathrm{C}-\mathrm{O}$ bond rupture in monohydrated $3{ }^{\prime}-\mathrm{dCMPH}$. Although one water molecule does not mimic the bulk water environment, it can indicate the qualitative trends. Among the various possible monohydrated isomers, we have taken the structure where the water molecule is directly hydrogen-bonded to the phosphate group (See Figure S5). The cartesian coordinate of the optimized neutral and anionic structure is presented on pages 1617.

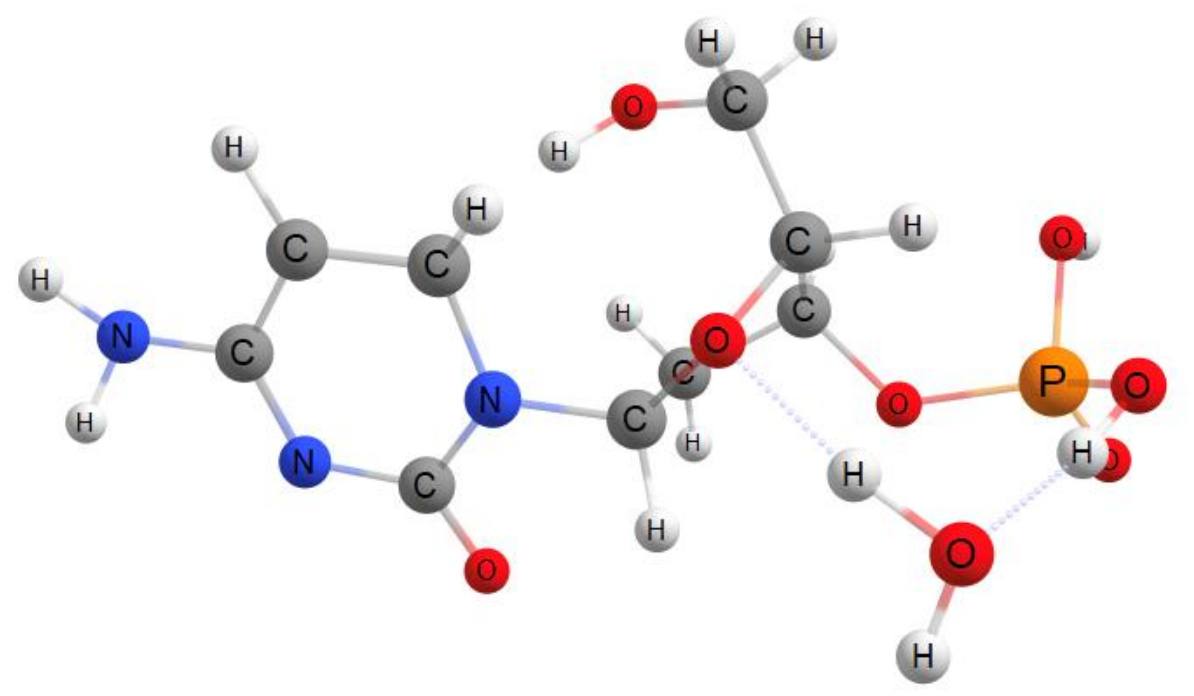

Figure S5. The structure of monohydrated 3'-dCMPH.

The adiabatic and diabatic potential energy curves corresponding to the linear transition from the dipole-bound to the valence $\pi^{*}$-type states are presented in Figure S6. The coupling constant has been found to be $4.5 \mathrm{meV}$, and the rate of transition from the dipole-bound to the valence $\pi^{*}$-type state has been found to be $1.58 \times 10^{10} \mathrm{~s}^{-1}$. It shows that even the presence of one water molecule can lead to almost a thousand times increase in the rate of formation of the stable valence $\pi^{*}$-type state. 


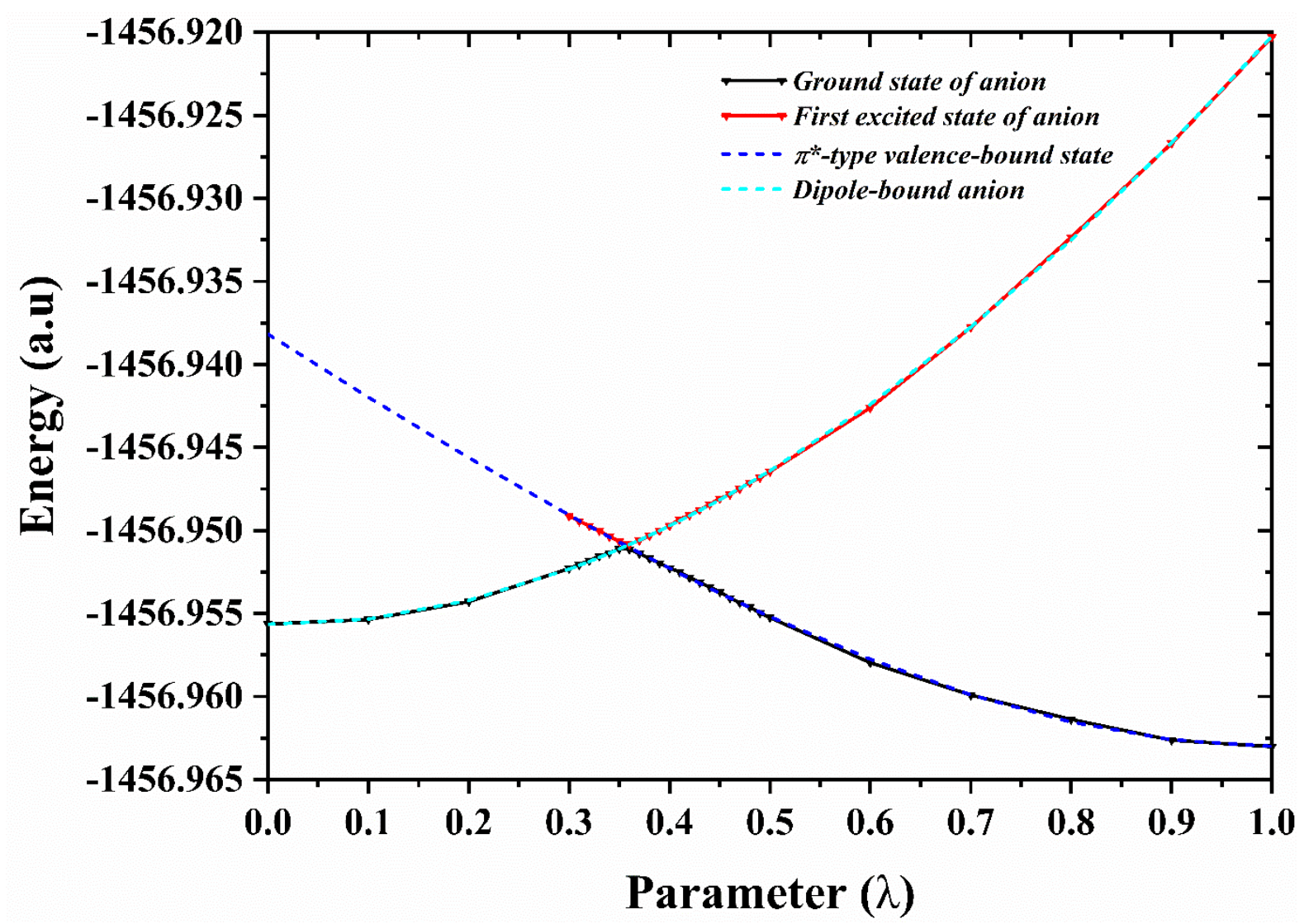

Figure S6. The adiabatic and diabatic PECs corresponding to the linear transition from the dipole-bound to the $\pi^{*}$-type valence bound state in monohydrated 3'-dCMPH.

Figure $\mathrm{S} 7$ presents the adiabatic and diabatic $\mathrm{PEC}$ corresponding to the $\mathrm{C}-\mathrm{O}$ bond stretching in monohydrated 3'-dCMPH. The coupling constant has been found to be $27.6 \mathrm{meV}$, and the rate of electron transfer from the dipole-bound to the dissociative valence $\sigma^{*}$-type state has been found to be $4.427 \times 10^{-6} \mathrm{~s}^{-1}$, which is several-fold less than that observed in the gas phase. It shows that the presence of a single water molecule enhances the rate of the formation of the stable valence $\pi^{*}$-type bound states and decreases the rate formation of the dissociative valence $\sigma^{*}$-type state. The overall effect will be the suppression of the electron attachment induced $\mathrm{C}-\mathrm{O}$ bond breaking in $3^{\prime}-\mathrm{dCMPH}$. 


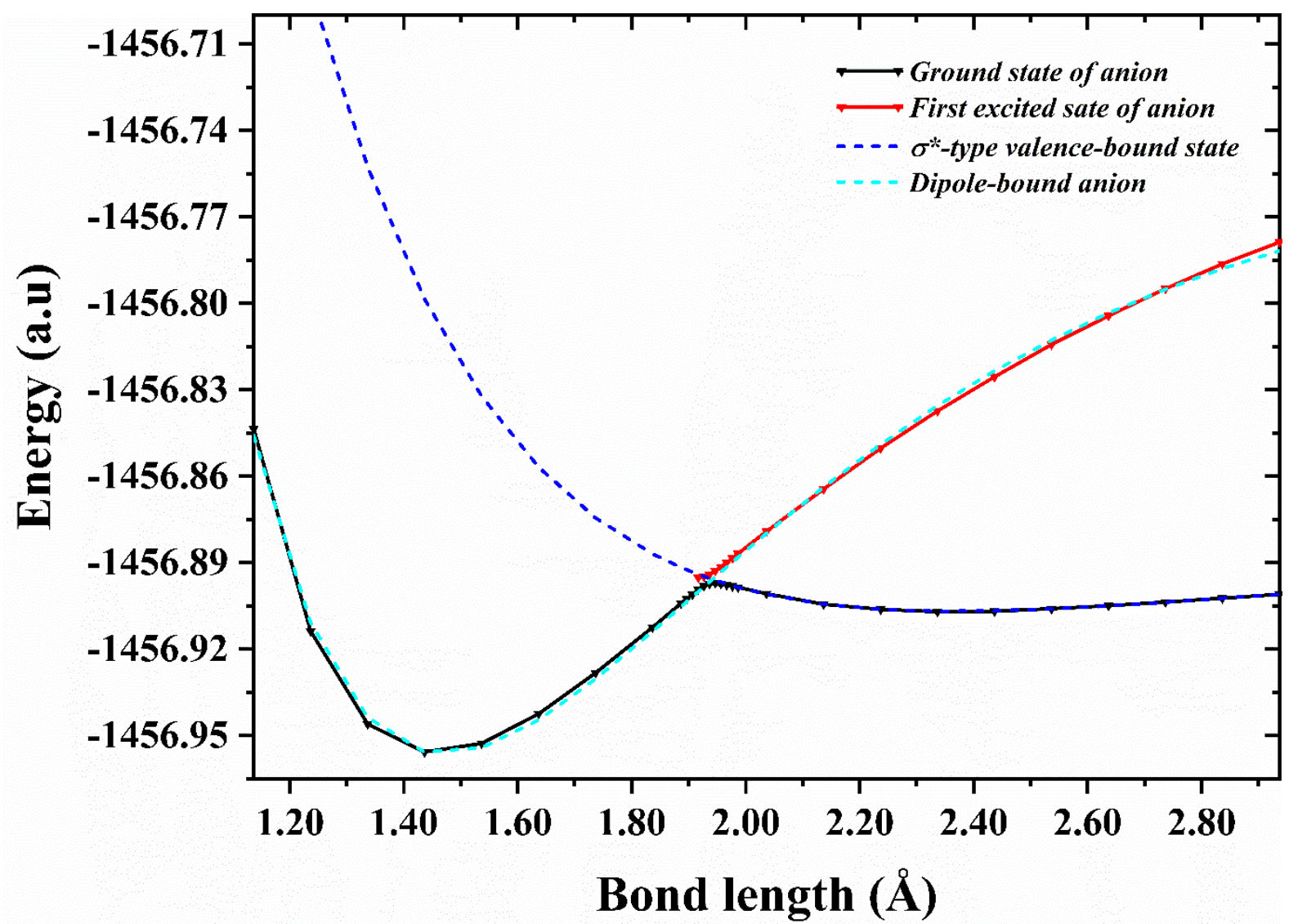

Figure S7. Adiabatic and diabatic PECs for $C-O$ bond dissociation from the dipole-bound state of monohydrated 3 '-dCMPH.

Cartesian Coordinates optimized at RI-MP2 level of theory using def2-TZVP basis set $3^{\prime}-\mathrm{dCMPH}\left(\mathrm{H}_{2} \mathrm{O}\right)$ neutral
C $\quad 0.000000$
0.000000
0.000000
C 0.000000
0.000000
1.533109
O 1.357060
0.000000
1.952515
C $\quad 2.220869$
0.230957
0.810302
C 1.433474
$-0.361186$
$-0.347807$
N $\quad-0.675415$
1.181864
2.097345
C -0.062807
2.038794
2.945083
C $\quad-0.723936$
3.125994
3.424370
C $\quad-2.078379$
3.284388
3.000027
N -2.702787
2.418754
2.232827
C -2.054948
1.303955
1.779887
O -2.571322
0.413724
1.120213
N -2.766192
4.394509
3.372363
C 2.611421
1.688746
0.637910
O 1.576629
2.545472
0.186205 

$\begin{array}{llll}\mathrm{O} & 1.487594 & -1.796743 & -0.339257\end{array}$
$\begin{array}{llll}\text { P } & 2.763591 & -2.660950 & -0.778462\end{array}$
$\begin{array}{llll}\text { O } & 3.415987 & -1.844999 & -1.986749\end{array}$
$\begin{array}{llll}\mathrm{O} & 2.376505 & -4.039670 & -1.081054\end{array}$
$\begin{array}{llll}\text { O } & 3.848662 & -2.410965 & 0.336234\end{array}$
$\begin{array}{llll}\text { O } & 2.545640 & -2.488851 & 2.670448\end{array}$
$\begin{array}{llll}\mathrm{H} & 3.396133 & 1.725885 & -0.122397\end{array}$
$\begin{array}{llll}\mathrm{H} & 3.046531 & 2.044569 & 1.578575\end{array}$
$\begin{array}{llll}\mathrm{H} & 3.139725 & -0.322743 & 1.006398\end{array}$
$\begin{array}{llll}\mathrm{H} & -0.493693 & -0.882553 & 1.946203\end{array}$
$\begin{array}{llll}\mathrm{H} & -0.244881 & 0.990467 & -0.378186\end{array}$
$\begin{array}{llll}\mathrm{H} & -0.702990 & -0.724448 & -0.401919\end{array}$
$\begin{array}{llll}\mathrm{H} & 1.758911 & 0.019350 & -1.317697\end{array}$
$\begin{array}{llll}\mathrm{H} & 0.959200 & 1.798641 & 3.208384\end{array}$
$\begin{array}{llll}\mathrm{H} & -0.236872 & 3.820298 & 4.094371\end{array}$
$\begin{array}{llll}\mathrm{H} & -3.757266 & 4.388505 & 3.185451\end{array}$
$\begin{array}{llll}\mathrm{H} & -2.432535 & 4.953411 & 4.138522\end{array}$
$\begin{array}{llll}\mathrm{H} & 1.048724 & 2.823554 & 0.946646\end{array}$
$\begin{array}{llll}\mathrm{H} & 3.465834 & -2.556276 & 1.243030\end{array}$
$\begin{array}{llll}\mathrm{H} & 3.331954 & -2.358579 & -2.802621\end{array}$
$\begin{array}{llll}\mathrm{H} & 2.005885 & -1.678032 & 2.607629\end{array}$
$\begin{array}{llll}\mathrm{H} & 1.918430 & -3.216875 & 2.755606\end{array}$

\section{$3^{\prime}$-dCMPH( $\left(\mathrm{H}_{2} \mathrm{O}\right)$ anion}
C $\quad 0.000000$
0.000000
0.000000
C $\quad 0.000000$
0.000000
1.534588
O 1.391699
$0.000000 \quad 1.927848$
C 2.240676
0.126139
0.768837
C 1.403561
$-0.421142$
$-0.378178$
N -0.678445
1.122632
2.132540
C $\quad 0.020265$
2.347251
2.278121
C -0.800891
3.443939
2.633479
C -2.172616
3.275830
2.643882
N -2.820646
2.131448
2.384474
C -2.082228
1.037426
2.065364
O -2.577376
$-0.048490$
1.719044
$\mathrm{N} \quad-3.024372$
4.366289
2.896273
C 2.727634
1.551319
0.536652
O 1.781121
2.436207
$-0.007518$
O 1.407453
$-1.870285$
$-0.419132$
$\begin{array}{lll}\text { P } & 2.693699 & -2.760872\end{array}$
$-0.713494$
O $3.694172-1.804793$
$-1.534241$
O 2.363053
$-3.999836$
$-1.428192$
O $\quad 3.458824 \quad-2.888035$
0.650742
O 1.949174
$-2.486373$
2.746240
H 3.560212
1.492140
$-0.172958$
H 3.129767
1.917494
1.491722 


$\begin{array}{rrrr}\mathrm{H} & 3.123784 & -0.488424 & 0.965417 \\ \mathrm{H} & -0.463738 & -0.906760 & 1.924202 \\ \mathrm{H} & -0.195091 & 1.007976 & -0.363829 \\ \mathrm{H} & -0.751977 & -0.682473 & -0.391218 \\ \mathrm{H} & 1.734271 & -0.038622 & -1.344467 \\ \mathrm{H} & 0.993517 & 2.235540 & 2.759883 \\ \mathrm{H} & -0.355647 & 4.404455 & 2.864856 \\ \mathrm{H} & -3.921296 & 4.022027 & 3.216793 \\ \mathrm{H} & -2.624441 & 5.029616 & 3.546361 \\ \mathrm{H} & 1.083036 & 2.575330 & 0.701235 \\ \mathrm{H} & 2.868482 & -2.816981 & 1.461006 \\ \mathrm{H} & 3.729644 & -2.121384 & -2.447083 \\ \mathrm{H} & 1.701547 & -1.539219 & 2.584160 \\ \mathrm{H} & 1.108689 & -2.958292 & 2.776841\end{array}$

\section{Reference}

1. Hanwell, M. D.; Curtis, D. E.; Lonie, D. C.; Vandermeersch, T.; Zurek, E.; Hutchison, G. R. Avogadro: An Advanced Semantic Chemical Editor, Visualization, and Analysis Platform. J. Cheminformatics 2012, 4, 17.

2. Neese, F. The ORCA Program System. Wiley Interdiscip. Rev. Comput. Mol. Sci. 2012, 2, 73-78.

3. Shavitt, I.; Bartlett, R. J. Many-Body Methods in Chemistry and Physics: MBPT and Coupled-Cluster Theory; Cambridge Molecular Science; Cambridge University Press: Cambridge, 2009.

4. Musial, M.; Bartlett, R. J. Multireference Fock-Space Coupled-Cluster and Equation-ofMotion Coupled-Cluster Theories: The Detailed Interconnections. J. Chem. Phys. 2008, $129,134105$.

5. Ghose, K. B.; Pal, S. Multireference Coupled Cluster Calculations on CH2+. J. Chem. Phys. 1998, 97, 3863.

6. Dutta, A. K.; Dar, M.; Vaval, N.; Pal, S. Structure, Stability, and Properties of the Trans Peroxo Nitrate Radical: The Importance of Nondynamic Correlation. J. Phys. Chem. A 2014, 118, 1350-1362. 